REVISTA DE ESTUDOS EM ARTES CÊNICAS

E-ISSN 2358.6958

\title{
A crítica e o Serviço Nacional de Teatro do Absurdo: Bárbara Heliodora no SNT
}

\author{
Angélica Ricci Camargo
}

\section{Para citar este artigo:}

CAMARGO, Angélica Ricci. A crítica e o Serviço Nacional de Teatro do Absurdo: Bárbara Heliodora no SNT. Urdimento - Revista de Estudos em Artes Cênicas, Florianópolis, v. 3, n. 42, dez. 2021.

doi DOI: http:/dx.doi.org/10.5965/1414573103422021e0203

Este artigo passou pelo Plagiarism Detection Software | iThenticate 


\title{
A crítica e o Serviço Nacional de Teatro do Absurdo: Bárbara Heliodora no SNT
}

Angélica Ricci Camargo ${ }^{1}$

\section{Resumo}

Este artigo apresenta algumas iniciativas empreendidas pela crítica teatral Bárbara Heliodora na direção do Serviço Nacional de Teatro (SNT) durante os primeiros anos da ditadura militar (1964-1967). Ao assumir o órgão federal dedicado ao estímulo ao teatro, a crítica carioca conferiu um sentido cultural e educativo às suas atividades, em sintonia com as ideias defendidas em seus textos e compartilhadas com outros críticos e representantes do setor, rompendo com algumas práticas realizadas desde a sua criação na década de 1930.

Palavras-Chave: História do Teatro Brasileiro. Bárbara Heliodora (1923-2015). Serviço Nacional de Teatro (SNT).

The theater critic and the National Theater of the Absurd Service: Bárbara Heliodora at the SNT

\begin{abstract}
This article presents some initiatives undertaken by the theater critic Bárbara Heliodora as a director of the National Theater Service (SNT) during the first years of the military dictatorship (1964-1967). In these years, the critic gave a cultural and educational meaning to the institution's activities, according to the ideas present in her texts and shared with other critics and professionals, changing practices carried out since its creation in the 1930s.
\end{abstract}

Keywords: History of Brazilian Theater. Bárbara Heliodora (1923-2015). National Theater Service (SNT).

La crítica de teatro y el Servicio Nacional de Teatro del Absurdo:

Barbara Heliodora en el SNT

\section{Resumen}

Este artículo presenta algunas acciones realizadas por la crítica de teatro Bárbara Heliodora como directora del Servicio Nacional de Teatro (SNT) durante los primeros años de la dictadura militar (1964-1967). La crítica dio un sentido cultural y educativo a las actividades de la institución, de acuerdo con las ideas defendidas en sus textos y compartidas con otros críticos y representantes del sector teatral, rompiendo con algunas prácticas observadas desde su creación en la década de 1930.

Palabras clave: Historia del Teatro Brasileño. Bárbara Heliodora (1923-2015). Servicio Nacional de Teatro (SNT).

${ }^{1}$ Doutora em História Social pela Universidade Federal do Rio de Janeiro (UFRJ). Mestrado em História Social pela mesma Universidade. Graduação em História pela Universidade Estadual Paulista Júlio de Mesquita Filho. Pesquisadora do Programa Memória da Administração Pública Brasileira - MAPA/Arquivo Nacional. angelicaricci@gmail.com

http://lattes.cnpq.br/8598519738231007

https://orcid.org/0000-0002-0234-3432 
Atuando na imprensa desde a segunda metade da década de 1950, Bárbara Heliodora (1923-2015) dedicou um grande espaço, em suas colunas, à avaliação dos órgãos públicos destinados à promoção do teatro brasileiro. Para além do exercício da crítica de espetáculos, ela, como outros colegas de profissão, examinou as modalidades da ação oficial e tratou de questões que ultrapassavam os limites dos palcos, mas que impactavam direta ou indiretamente nas realizações que apreciava.

Para esta análise, buscou-se recuperar, nesses textos, alguns temas que se tornaram eixos centrais de sua atuação como diretora do Serviço Nacional de Teatro (SNT), especialmente aqueles relacionados à escola pertencente ao órgão e à concessão de subvenções. Em um segundo momento, voltou-se a atenção para a sua gestão, que compreendeu os anos de 1964 a 1967.

Nesse percurso, observou-se como muitas de suas ideias eram compartilhadas com diversos personagens do setor teatral, sobretudo os críticos contemporâneos que se uniram em torno do Círculo Independente de críticos Teatrais (CICT) em 1958. Engajados na divulgação de um teatro de "maior qualidade artística" em detrimento do chamado "velho teatro de comédia" ainda presente nos palcos, os críticos cariocas, como os paulistas, ocuparam cargos públicos, assumindo papéis no interior da política institucional (Cruz, 2000). Nos novos espaços, esses personagens tentaram concretizar muitas das propostas defendidas nas páginas de jornais e revistas. Em alguns casos, encontraram maior receptividade. Em outros, os entraves burocráticos e a instabilidade políticainstitucional sobressaíram-se às conquistas, que tiveram um caráter temporário.

Apesar de sua longa e conhecida presença na história do teatro brasileiro, seja como crítica, professora ou especialista e tradutora da obra de William Shakespeare, a trajetória de Bárbara Heliodora mereceu pouca atenção dos estudiosos (Lugão, 2006, Lima Filho, 2018), talvez provocada pelas polêmicas que se envolveu durante as décadas de trabalho na imprensa, que acabaram conferindo-the a reputação de crítica "temível" e "conservadora" (Torres, 2015). Assim, suas críticas e textos são um vasto material pouco explorado em seu conjunto, diferente do que ocorreu com outros críticos contemporâneos, como Décio de Almeida Prado, Sábato Magaldi, Paulo Francis e Yan Michalski. 
Sua atuação no SNT, que the rendeu a "fama de reacionária e ditatorial" (Heliodora, 2013), é menos conhecida, como a própria história do órgão nesse período, ao menos no espaço de tempo que antecedeu a gestão de Orlando Miranda (Garcia, 2013; Lopes, 2020).

Os estudos sobre órgãos e instituições culturais têm assumido, frequentemente, uma “marca personalista” (Denizot, 2005, p.73), de forma que é comum encontrarmos trabalhos que se concentram em determinados recortes temporais e indivíduos, como é o caso deste artigo, o que nos leva a refletir, rapidamente, sobre aspectos mais gerais da relação entre os poderes públicos e a cultura e as políticas culturais.

Política cultural pode ser definida, de forma ampla, como um conjunto de intervenções realizadas pelo Estado ou por outras instituições na esfera cultural. Para alguns autores, no entanto, política cultural não se resume às distintas formas de amparo das artes pelos governos, mas se constitui como uma ação global, coerente e organizada (Dubois, 1999). Sem aprofundar nas discussões conceituais, vale assinalar que, no Brasil, as políticas culturais têm sido caracterizadas, de acordo com Rubim (2010), pelo autoritarismo, instabilidade e ausência. Essa série de fatores explica, em parte, o interesse concedido a algumas figuras, notadamente as que foram responsáveis pela formulação e/ou execução de trabalhos considerados "bem-sucedidos", seja pelo legado deixado em termos administrativos ou no plano das ideias. Entretanto, não se pode perder de vista os contextos cultural e político-administrativo e a história das instituições, que se constituem como elementos essenciais para a análise das iniciativas empreendidas.

Assim, ainda que o estudo biográfico e o exame da sua produção intelectual estivessem fora dos objetivos deste texto, procurou-se esboçar alguns traços da trajetória de Bárbara Heliodora e de suas redes de relações para elucidar aspectos relativos à sua concepção de teatro e às suas propostas para o SNT. Fez-se, também, necessário apontar algumas questões relacionadas à singularidade do contexto político, com o fim de demarcar os limites e condicionantes impostos a uma estrutura da administração pública, além de recapitular alguns episódios da história do SNT e das lutas do campo teatral nas décadas anteriores à sua gestão 
(Miceli, 1985, p.9-33).

Para tal tarefa, foram usados como fontes os textos de Bárbara Heliodora presentes na coletânea organizada por Cláudia Braga (2007), uma pequena parcela da documentação produzida pelo SNT, particularmente os planos e relatórios anuais, ${ }^{2}$ matérias jornalísticas contemporâneas à sua atuação e entrevistas concedidas pela crítica, incluindo uma à autora deste artigo em 2013.

Sem pretender esgotar o assunto, buscou-se contribuir para o conhecimento de uma instituição cultural criada em 1937, no governo de Getúlio Vargas, e extinta após inúmeras transformações somente em 1990, e demarcar o papel de alguns personagens e de ideias presentes nos debates sobre políticas para cultura.

\section{A crítica, os críticos e o SNT}

Filha de Marcos Carneiro de Mendonça, jogador de futebol e historiador, e de Ana Amélia Carneiro de Mendonça, poetisa e uma das fundadoras da Casa do Estudante do Brasil, Heliodora Carneiro de Mendonça, conhecida como Bárbara Heliodora, desde cedo vivenciou um rico ambiente intelectual (Heliodora, 2014). Aos 17 anos, ingressou na antiga Faculdade de Filosofia da Universidade do Brasil. Em 1941 recebeu uma bolsa para estudar no Connecticut College, nos Estados Unidos, onde permaneceu por dois anos e teve maior contato com a obra de Shakespeare e com o teatro, obtendo o bacharelado em língua e literatura inglesas (Leão, 2020; Braga, 2007, p.17).

Após a conclusão dos estudos, experimentou os palcos e escreveu textos sobre Shakespeare e outros temas. A estreia na crítica se deu em 1957 no jornal Tribuna da Imprensa, onde ficou por pouco tempo. Apesar da forte presença feminina em cena e na liderança de companhias, como evocam os nomes de Dulcina de Moraes, Eva Todor, Maria Della Costa, Bibi Ferreira, Cacilda Becker e tantas mais, em outras esferas do setor teatral os espaços eram mais restritos para as mulheres. Isso pode ser observado na dramaturgia, ainda que mereçam ser citadas Maria Jacinta e Maria Clara Machado, entre outras; na direção de

${ }^{2}$ Documentação custodiada pelo Centro de Documentação da Fundação Nacional das Artes (Cedoc/Funarte). 
espetáculos, cabendo aqui lembrar o trabalho pioneiro de Esther Leão; e na crítica, onde atuavam Luiza Barreto Leite, Claude Vincent e Zora Seljan (Da Rin, 1995; Pontes, 2010).

Em março de 1958 Bárbara Heliodora foi convidada para trabalhar no Suplemento Dominical do Jornal do Brasil. No novo emprego encontrou resistências por parte de um dos críticos mais antigos do país em atividade, Mário Nunes (Leão, 2020). Além da defesa de seu espaço no jornal, que, aliás, era compartilhado com outros críticos, a resistência de Mário Nunes pode ser pensada em termos de um conflito entre perspectivas sobre o papel desses profissionais, que refletia as transformações que se processavam no âmbito da crítica teatral carioca naquele momento (Junqueira, 2004, p.199).

O estudo da crítica teatral e de seus personagens vem ganhando destaque nos últimos anos (Bernstein, Junqueira, 2013; Lima, Ciotti, 2016). De acordo com vários pesquisadores, a partir da década de 1940, contexto de aparecimento de experiências de renovação observadas nos espetáculos produzidos por grupos amadores, surgiu uma geração de críticos dotada de uma "nova mentalidade". O expoente dessa geração foi Décio de Almeida Prado, que trabalhou na revista Clima e no jornal O Estado de S. Paulo a partir de 1946. O crítico paulista distinguia-se de muitos profissionais por sua preocupação com a criação de uma "consciência teatral", que imprimiu aos seus primeiros escritos um caráter informativo e didático, privilegiando a abordagem histórica, ao situar o autor e a peça em seu contexto literário e social (Bernstein, Junqueira, 2013, p.167). Além disso, Décio de Almeida Prado se engajou em um projeto de modernização da cena brasileira, combatendo os "vícios" do teatro profissional que dominava os palcos. Essa tomada de posição foi acompanhada da prática no Grupo Universitário de Teatro (GUT) e como professor na Escola de Arte Dramática (EAD) fundada em 1948.

O trabalho rigoroso de Décio de Almeida Prado serviu de referência para outros críticos, como Bárbara Heliodora e Henrique Oscar (Heliodora, 2013; Brasil, 1977, p.62), que exerciam a profissão na capital federal, onde esse combate contra o "velho" teatro profissional foi mais aguerrido, por lá se concentrarem as mais importantes companhias de comédia (Bernstein, Junqueira, 2013, p.173). Tais companhias eram, com frequência, alvos de avaliação negativa por parte da crítica 
teatral em geral, embora fossem tratadas, em alguns casos, com certa condescendência, que associava o seu êxito à "incultura" do público. Essa discussão evidenciava uma visão hierarquizada dos gêneros teatrais, presente nos debates intelectuais desde o século XIX, que dividia a produção artística entre um teatro "sério" ou "de arte", caracterizado por qualidades literárias eruditas, e o teatro "para rir" ou "comercial", ligado às formas tradicionais de comicidade (Camargo, 2017, p.30).

A cidade do Rio de Janeiro congregava o maior número de companhias tradicionais e era a sede das entidades teatrais mais antigas e influentes, como a Sociedade Brasileira de Autores Teatrais (SBAT), o Sindicato dos Atores, Cenógrafos e Cenotécnicos do Rio de Janeiro (Casa dos Artistas) e a Associação Brasileira de Críticos Teatrais (ABCT). A cidade também abrigava o órgão federal destinado ao desenvolvimento do teatro brasileiro, o SNT, que distribuía subvenções disputadas pelas companhias mais "antigas" e grupos "modernos", que se consolidavam profissionalmente desde a segunda metade da década de 1940 (Camargo, 2017, p.2).

Em 1958, os críticos identificados com estes últimos deixaram a ABCT para fundar uma nova entidade, o CICT, que congregou nomes como Bárbara Heliodora, Henrique Oscar, Paulo Francis, Gustavo Dória e Brício de Abreu. A despeito das discordâncias políticas e de ideias, a defesa de um novo papel para a crítica guiou o estabelecimento do CICT, como pode ser observado neste texto escrito por Bárbara Heliodora:

O Brasil atravessa uma fase decisiva para o teatro [...] e, aos poucos, vai aparecendo um público que quer ver teatro de bons textos, um público que começa a sentir o que é a verdadeira qualidade do espetáculo. Esse público é tão necessário quanto o esforço que vem sendo feito por alguns grupos para apresentar bom teatro, e foi pela necessidade de servir tanto a esse público quanto aos que trabalham no sentido de realização de um teatro de categoria que durante este ano de 1958 tornou-se inevitável uma definição da crítica teatral, que culminou com a cisão que determinou a fundação de uma nova entidade: o Círculo Independente de Críticos Teatrais do Rio de Janeiro (apud Bernstein, Junqueira, 2013, p.172).

Além de distribuir prêmios para os "melhores do ano", como fazia a ABCT, os 
membros do CICT, que foram chamados naquele momento de "nova crítica", procuravam orientar o público em suas colunas, atuando como intelectuais mediadores (Gomes; Hansen, 2016), ao apontar os espetáculos que mereciam ser vistos, que, de modo geral, eram aqueles que traziam preocupações "mais elevadas", fosse no repertório ou montagem. Para Bárbara Heliodora, a obrigação do crítico era, portanto, "servir ao teatro no sentido de seu aprimoramento artístico consciente, no sentido de sua existência viva dentro da realidade de sua época" (2007, p. 83). ${ }^{3}$ Esse teatro “aprimorado", tinha, por sua vez, um papel pedagógico, cabendo-lhe a "melhoria do nível cultural de nosso povo (2007, p.204). ${ }^{4}$ Daí não haver espaço para concessões e para o elogio publicitário, atitude que, segundo Paulo Francis, desmoralizava por completa a função da crítica, por colocar o bom e o mau em um mesmo plano de igualdade (Bernstein, Junqueira, 2013, p.197).

Tal preocupação ganhou forma de um projeto coletivo (Velho, 1994, p.47) dentro do CICT, a partir da promoção de cursos de formação de plateia, compreendendo temas relacionados à história e à teoria teatral, que foram ministrados por Décio de Almeida Prado, Anatol Rosenfeld, Sábado Magaldi, Adolfo Celi, Fernanda Montenegro, entre outros (Brasil, 1977, p.64). Projeto que, de certa forma, ganhou uma dimensão política em seu sentido mais estrito, com a inserção de seus membros nos espaços institucionais existentes, como o conselho Consultivo de Teatro (CCT) do SNT, e, posteriormente, com a nomeação de Bárbara Heliodora para a direção do órgão. ${ }^{5}$

O SNT que, desde a sua criação, foi comandado, na maior parte do tempo, por figuras ligadas ao meio teatral, acumulou uma ampla gama de competências voltadas para a promoção do teatro brasileiro (Dionysos, 1967, p.54-86). Foi responsável por realizações pioneiras, como o estabelecimento de uma escola e de companhias oficiais, contudo, a atividade que ganhou mais destaque foi a concessão de subvenções. Esta prática, por essência arbitrária, mobilizou artistas

\footnotetext{
${ }^{3}$ Optou-se por colocar notas com os nomes dos artigos presentes na coletânea organizada por Braga (2007), assim como a data original de sua publicação. Para este caso, ver: Por que somos críticos? [13 de março de 1960].

${ }^{4}$ Vamos criteriosamente ao teatro [17 de junho de 1961].

${ }^{5}$ O CICT encerrou suas atividades em dezembro de 1965, motivado por diversos fatores, "especialmente a estagnação das atividades culturais devido à falta de tempo dos integrantes” (Bernstein, Junqueira, 2013, p.173)
} 
e entidades, provocando grandes disputas e polêmicas, que contribuíram para fragilizar o papel do órgão, ao qual se somaram outros fatores como o baixo orçamento e a descontinuidade das ações decorrente da instabilidade política e administrativa (Camargo, 2017, p.258).

No que se refere às subvenções, um dos pontos mais questionados era o da falta de critérios. O primeiro diretor do SNT, o dramaturgo e crítico teatral Abadie Faria Rosa, defendia a ideia de "elevar" o teatro nacional, promovendo um repertório mais "sério". Mas, a falta de clareza nas suas propostas, a "influência" das relações pessoais e a interferência das autoridades superiores acabou por conferir às subvenções um caráter plural, servindo para amparar um teatro considerado sem maiores pretensões "artísticas", como o teatro de revista - que nem era considerado "teatro" pelo próprio diretor -, e os projetos de grupos amadores que traziam novas ideias para os palcos, como ocorreu com Os Comediantes (Camargo, 2017, p.52).

Nos anos que se sucederam à gestão de Abadie Faria Rosa, os problemas continuaram, mas houve tentativas de contorná-los. Em 1949, foi aprovada uma portaria, elaborada pelo diretor Thiers Martins Moreira, que colocou como exigência aos pleitos a inclusão de peças nacionais de "valor artístico". Essa exigência motivou a revolta de artistas e personalidades, e não foi plenamente cumprida. Em 1951, o diretor Aldo Calvet adotou uma nova solução, a criação de um conselho composto por representantes de classe para deliberar sobre as concessões, o CCT (Camargo, 2017, p.97-98 e p.138).

A presença de interessados diretos nos auxílios no CCT que, inicialmente, foi formado por figuras do Rio de Janeiro, e as divergências entre as posições de seus componentes levaram o diretor a considerar a iniciativa um fracasso. No entanto, - conselho conseguiu perdurar por mais de uma década, agregando novos membros, especialmente de São Paulo, onde o movimento teatral crescia de forma intensa. A discussão sobre os critérios ou a ausência deles foi retomada em várias ocasiões, mas, a tendência foi distribuir um número cada vez maior de subvenções, com valores menores, até irrisórios (Camargo, 2017).

Essa característica quase "assistencial" que ganhou forma nesses anos foi 
objeto do olhar atento de Bárbara Heliodora que, entre 1957 e 1964, condenou a falta de orientação do órgão, que nesses anos foi dirigido por Edmundo Moniz (1956-1961 e 1961-1963), Clóvis Garcia (1961) e Roberto Freire (1963-1964).

Em seus escritos sobre o assunto, Bárbara Heliodora defendeu a definição de um critério "cultural" para as subvenções e questionou os auxílios concedidos aos circos-teatros e a nomes como Dercy Gonçalves e Oscarito, que se dedicavam a um gênero "popular", além de atentar para os valores recebidos, que eram "ridículos e inoperantes" (2007, p.610-612), tornando o SNT:

uma espécie de serviço de assistência social da classe teatral, com a obrigação de contribuir com o seu quinhão para o mantenimento de toda e qualquer organização teatral simplesmente a título de ajuda à subsistência dessas companhias, baseada na simples razão de que a continuação dessas companhias dá emprego a vários profissionais (2007, p.612). ${ }^{6}$

A reclamação sobre a falta de critérios tocava em um ponto importante e sempre problemático no que se refere à concessão de dinheiro público para iniciativas privadas, mas ganha contornos de polêmica quando se trata da esfera cultural, refletindo o estatuto ainda hoje bastante periférico ocupado pela área nas políticas governamentais. Por outro lado, evidenciava a referida visão hierarquizada, que considerava determinados gêneros ou espetáculos em um patamar superior, dando primazia ao texto (Guzik, 2008, p.146). Mesmo a justificativa de que as montagens "populares" contavam com público capaz de pagar as despesas não escondia o pouco apreço dos críticos por elas.

Bárbara Heliodora também se manifestou contra o estado de abandono da escola mantida pelo SNT, o Conservatório Nacional de Teatro, que demandava urgentemente uma reforma física e didática, mas foi "esquecido" no contexto da criação da Campanha Nacional de Teatro, que implicou um aumento do orçamento do órgão a partir de 1958 (2007, p. 665-671). ${ }^{7}$ Outro alvo de suas condenações foi o da falta de planejamento da companhia oficial, o Teatro

${ }^{6}$ As subvenções do Serviço Nacional de Teatro [21 set. 1958].

${ }^{7}$ Consequências graves da falta de orientação do SNT [5 de setembro de 1959]. 
Nacional de Comédia (TNC) (1956-1967), que impactou negativamente o empreendimento, que contou com a participação de diretores prestigiados como Gianni Ratto e Zbigniew Ziembinski.

Mesmo com todas essas ressalvas, a crítica parecia acreditar na importância do órgão, e denunciou, em 1958, o projeto, apoiado pelo Sindicato dos Atores Teatrais do Rio de Janeiro, que visava transferir para o Congresso Nacional parte da distribuição de verbas destinadas ao auxílio de companhias e grupos. Para ela, a proposta reduziria as subvenções "aos sistemas de pedidos a parlamentares que, fatalmente, cederiam a influências de informantes interessados, já que não eram técnicos em assuntos de teatro" (2007, p.604-605). ${ }^{8}$

Em 1961, a crítica contribuiu na apreciação do plano de ação idealizado por Clóvis Garcia, fazendo considerações que seriam retomadas na sua administração. Dentre as sugestões figuravam o estabelecimento de "linhas culturais" para a concessão de subvenções, a nomeação de um conselho diretor para o TNC, a contratação de diretores para orientar grupos locais em todo o país, e a reestruturação do Conservatório (Mendonça, [1961]). Propostas que se assemelhavam a de colegas de profissão, veteranos e novos, como Henrique Oscar e Paulo Francis, que, na imprensa, manifestou-se a favor de um programa de verbas destinado a companhias teatrais com trabalho "sério", e a instituição de uma escola de teatro que admitisse alunos por mérito (Moura, 1996, p.122).

A saída de Clóvis Garcia, que pediu exoneração após a renúncia do presidente Jânio Quadros, dividiu o setor teatral carioca. O lado que pleiteou a recondução do crítico paulista ao cargo, formado por Bárbara Heliodora e seus colegas do CICT, entre outros, acabou vencido em decorrência da nomeação de Edmundo Moniz, apoiado por várias personalidades do chamado "velho teatro". Depois dele, o dramaturgo e psicanalista Roberto Freire assumiu a cadeira, em uma gestão que dialogou mais diretamente com as experiências de teatro popular e político que apareceram no período (Camargo, 2017, p.225-231).

Com a saída de Freire, no governo de João Goulart, o panorama era de desalento, o que levou Bárbara Heliodora, em janeiro de 1964, a desaconselhar a

${ }^{8}$ Momento perigoso para o teatro nacional [17 ago. 1958]. 
nomeação de alguém para o cargo:

\begin{abstract}
A verdade pura e simples é que o teatro nacional pode desistir de esperar qualquer auxílio, apoio ou estímulo por parte do SNT, serviço que não existe e para o qual, sinceramente, aconselhamos a todos os inúmeros futuros ministros da Educação e Cultura dos próximos meses ou anos a não nomear ninguém: quem quiser ter ilusões de fazer alguma coisa pelo Teatro Nacional inevitavelmente deixará o cargo após uma experiência muito breve [...].

Haverá, porventura, o eterno candidato, sempre pronto a ocupar o cargo fictício, num crescendo de alienação que, à guisa de justiça poética, transforma toda a situação numa espécie de pseudo-lonesco que nos dá o privilégio mundial de termos um Serviço Nacional de Teatro do Absurdo (2007, p.713). ${ }^{9}$
\end{abstract}

Mas, ironicamente, ela foi convidada a assumir a direção do SNT no governo inaugurado após o golpe civil-militar e acabou por ficar no órgão por quase três anos, como veremos a seguir.

\title{
Barbara Heliodora no SNT: a concretização de um projeto?
}

As questões relacionadas à cultura estiveram entre as preocupações do governo desde os anos iniciais do período ditatorial, no que se refere à reformulação do aparato censório e à expansão das medidas de estímulo, ainda que os maiores investimentos fossem vistos na década de 1970, com a implementação do Plano de Ação Cultural (PAC) e da Política Nacional de Cultura (PNC) (Calabre, 2009, p.76-81).

No governo de Castelo Branco houve a continuidade de políticas setoriais, com destaque para o estabelecimento do Instituto Nacional de Cinema (INC), em 1966. Naquele ano foi instituído um órgão dedicado à formulação da política cultural, o Conselho Federal de Cultura (CFC), para o qual foram convocadas figuras consagradas do campo intelectual, como Gilberto Freyre, Rachel de Queiroz, Ariano Suassuna, João Guimarães Rosa e Josué Montello. Esse movimento em direção ao poder foi comum a muitos artistas e intelectuais ao

\footnotetext{
${ }^{9}$ O triste destino do SNT [7 jan. 1964].
} 
longo de toda a ditadura, ganhando contornos complexos, pois, muitas vezes, esses artistas e intelectuais se posicionaram contra as ações do mesmo governo que integravam. De acordo com Maia (2012, p.39), o CFC se constituiu como um espaço tradicionalmente ocupado pelas elites culturais atuantes no Estado desde o primeiro governo Vargas e suas iniciativas destinaram-se à preservação, defesa e divulgação do patrimônio cultural, priorizando as áreas de arquitetura e literatura, e as comemorações de acontecimentos históricos e manifestações folclóricas.

As medidas efetuadas e a relativa liberdade de expressão experimentada vista, por exemplo, na montagem de espetáculos como Opinião, Liberdade, Liberdade e Arena Canta Zumbi, contribuíram para a construção de uma memória que, de certa forma, reduziu o impacto das medidas repressivas empreendidas no período inicial da ditadura. Período que, contudo, foi marcado por inúmeras perseguições e expurgos, que incluiu os movimentos culturais ligados às massas, como o Centro Popular de Cultura (CPC) da UNE; e pelo recrudescimento da censura, que seria centralizada em 1967 (Napolitano, 2017, p.61-62).

As transformações políticas afetaram de diferentes formas o setor teatral. Além da continuidade das propostas marcadas pelo engajamento que, em alguns casos, assumiram a postura de "resistência cultural" à ditadura, como evocam os espetáculos mencionados acima, observa-se o surgimento de montagens consideradas inovadoras, como O rei da vela, de Oswald de Andrade, feita pelo Teatro Oficina em 1967 (Betti, 2013).

No SNT ocorreu a nomeação de uma pessoa da área para o cargo de direção, demonstrando um certo interesse do governo pelas questões teatrais. Em mais de uma oportunidade, Bárbara Heliodora afirmou desconhecer o que motivou o convite feito pelo então ministro da Educação e Cultura, Flávio Suplicy de Lacerda, mas, na entrevista concedida em 2013, ela relatou que a indicação foi, provavelmente, sugerida pelo diretor da Biblioteca Nacional e ex-diretor do SNT, o escritor Adonias Aguiar Filho.

O convite não foi aceito de imediato, segundo ela: possibilidade. Mas, por outro lado, achei que seria covardia, já que eu tinha 
atacado tanto a política anterior, deixar de botar o pescoço de fora para outras pessoas cortarem também. Pelo menos eu ia tentar fazer o que me parecia um pouco mais lógico (Heliodora, 1980, p.80).

Bárbara Heliodora foi uma das poucas mulheres a ganhar posição de destaque na administração pública naquele momento. ${ }^{10}$ No próprio SNT, a despeito da presença feminina em cargos administrativos e como professoras do Conservatório, foram poucas mulheres convocadas para contribuir no Conselho Consultivo e instâncias de decisão (Camargo, 2017). Em outras esferas, vale lembrar a atuação de Maria Clara Machado, que comandou o Serviço de Teatro e Diversões do estado da Guanabara em 1961, e de Cacilda Becker, que presidiu a Comissão Estadual de Teatro de São Paulo em 1968.

A repercussão de sua nomeação parece ter sido positiva (Wolff, 1964, p.2). Yan Michalski, que substituiu Bárbara Heliodora no Jornal do Brasil, expressou sua confiança na seriedade da diretora, mas ponderou sobre os entraves burocráticos e políticos que a esperavam: a estrutura administrativa obsoleta, as frequentes alterações nas verbas destinadas ao órgão, a "inércia” do funcionalismo público e o caráter transitório do cargo (Michalski, 1964, p.3).

Após sua nomeação, que ocorreu em 18 de maio, Bárbara Heliodora divulgou suas ideias e planos, entre os quais figuravam a dinamização do ensino de teatro, a reformulação do Conservatório, a publicação de livros atualizados e o estabelecimento de critérios para as subvenções (Jornal do Brasil, 1964, p.13).

Na edição de julho e agosto da Revista da SBATfoi realçada a posição da nova diretora em relação ao CCT e sua crítica à ideia da subvenção como "direito de todos", incluindo espetáculos "sem nenhuma relação com a educação e a cultura" (Leite, 1964, p.15). Ao ser interpelada sobre a condição para que um espetáculo fosse considerado de qualidade, a diretora foi categórica: "o texto", embora também julgasse importantes elementos como a direção e o elenco. Nesse sentido, assegurou que não tinha interesse em auxiliar "peças para divertir, cujas plateias já estavam garantidas [...] [nem] gente que se proponha a grandes aventuras sem credencial alguma" (apud Leite, 1964, p.17). Outra questão levantada 
foi a implantação da assistência técnica, em vez de amparo financeiro a grupos amadores, porque, para ela “... a maior parte dos grupos amadores era uma vergonha para o país e precisavam ser orientados, pois a obrigação dos amadores era formar plateia e não futuros profissionais" (apud Leite, 1964, p.17).

Uma das primeiras medidas tomadas em relação às subvenções foi a extinção do Conselho Consultivo de Teatro, em julho de 1964, pondo fim a uma experiência de trabalho conjunta entre a repartição federal e o campo teatral. Vale destacar que ela não foi a primeira diretora a querer acabar com a instância de representação de classe. Mas, diferente do que aconteceu com alguns de seus antecessores, vencidos pela forte mobilização do setor, que levou o assunto às mais altas esferas da administração, ela obteve o apoio do ministro para concretizar sua intenção.

A pouca repercussão sobre o fato na imprensa e na documentação pesquisada indica, ainda, que a iniciativa foi favorecida pelo contexto político do pós-golpe e por um certo enfraquecimento do papel das entidades que compunham o conselho, cujas trajetórias carecem de estudos aprofundados. Um dos registros encontrados contra a extinção do CCT foi uma carta de Aristides de Basile, da Associação Paulista de Empresários de Teatro e Diversões (AETSP), ao presidente da República, que teve a seguinte resposta da diretora:

... Conselho que durante anos a fio pulverizou as parcas verbas [...], justamente por ter como membros pessoas que, como o sr. De Basile, tinham como maior interesse satisfazer os seus interesses, mesmo ao preço de impedir que um Serviço do Ministério da Educação e Cultura jamais se ativesse, na distribuição de auxílios ao teatro brasileiro, a questões de educação ou de cultura. Para ilustrar: nos anos de 1959, 60, 61, 62 e 63 [...] a mesma [AETSP] recebeu um total de Cr\$590.000,00 de auxílios do SNT [...]. Nada haveria nisso de extraordinário, mas o que é de estranhar é que muito embora a AETSP fale sempre de auxílios médicos, dentários e outros em seus pedidos, as prestações de contas que fez dos auxílios só mencionam pagamento de aluguéis, salários de secretários e até mesmo matéria paga nos jornais (Processo no 476/64).

Na exposição de motivos que se seguiu à portaria de extinção do Conselho, Bárbara Heliodora reafirmou as posições já divulgadas em seus artigos na imprensa, considerando que o critério adotado estava em desacordo com a nova 
orientação da direção, que pretendia incentivar o "aparecimento de novos autores brasileiros e a apresentação de espetáculos de alto nível artístico e cultural”. Os auxílios a espetáculos de teatro musicado (revista), que ocorriam "em detrimento da arte teatral”, também foram condenados (Processo no 157/64).

A supressão dessa instância, contudo, não fez com que a diretora descartasse a possibilidade de convocação de representantes do setor quando fosse necessário. Além disso, na estrutura do SNT havia o Conselho Consultivo da Campanha Nacional de Teatro, existente desde 1958, que cumpriria as funções de um órgão de consulta. Para compor esse conselho foram nomeados críticos e figuras de prestígio no campo da cultura e do teatro em particular, como Adonias Aguiar Filho, Carlos Drummond de Andrade, Décio de Almeida Prado, Gustavo Dória e Agostinho Olavo - os dois últimos funcionários do SNT.11

Em setembro, a portaria no 614 regulou a distribuição de auxílios para a montagem de espetáculos, visando "contribuir para a elevação do nível cultural e educativo da arte teatral, para facilitar a difusão [do teatro] em todo país e para estimular o trabalho do autor dramático nacional” (Brasil, 1964, p.8.585). As subvenções seriam dadas, sempre que possível, durante a produção, ficando obrigados as companhias e grupos contemplados a reduzir 50\% dos preços dos ingressos para estudantes e integrantes de entidades de classe uma vez por semana. Também foram previstas concessões para grupos amadores, que poderiam ser de natureza técnica ou didática; entidades ou instituições; e circos e pavilhões que incluíssem atividades teatrais em sua programação.

Em meio a organização de um novo edital, vários empresários cariocas buscaram a ajuda direta do presidente da República, alegando falta de condições de trabalho devido à crise decorrente da escassez de público (O Estado de S. Paulo, 1965, p.11).

O chamado auxílio de emergência ou extraordinário foi concedido com a verba do SNT, segundo Bárbara Heliodora, como um gesto pessoal de Castelo

11 Em 1966, Drummond foi substituído por outro ex-diretor do SNT, Thiers Martins Moreira, professor da Faculdade Nacional de Filosofia (Heliodora, 1967). 
Branco. ${ }^{12}$ O valor, de seis milhões de cruzeiros, não cobria os gastos com uma montagem, mas era bem maior do que o órgão normalmente concedia, tendo em vista que a tendência era repartir a verba ao máximo de companhias. Entretanto, não houve "consideração de qualidade artística ou condição financeira", o que era o oposto das mudanças ensaiadas pela diretora (O Estado de S. Paulo, 1965, p.11). ${ }^{13}$

No início de 1965 foi a vez dos empresários paulistas cobrarem a ajuda do governo. Em janeiro, Ruth Escobar, Sandro Polloni e Renato Borghi foram para o Rio conversar com Bárbara Heliodora e solicitar a concessão de verba extraordinária nos mesmos moldes, que saiu no mês seguinte ( $O$ Estado de $S$. Paulo, 1965, p.11). ${ }^{14}$

Com essas medidas discricionárias, sobrou pouco dinheiro para as subvenções concebidas a partir do edital, que foi lançado no final de dezembro de 1964, o que levou ao estabelecimento de um teto máximo de quatro milhões de cruzeiros, uma "contribuição insuficiente para tornar a ação do governo capaz de levar as companhias teatrais a se arriscarem em produções de grande porte e risco financeiro", como reforçou a diretora (Heliodora, 1966).

Durante sua gestão foram lançados dois editais por ano. Em geral, eles possuíam exigências similares aos editais anteriores, relativas à apresentação de documentos, indicação do local dos espetáculos, cópia do texto da peça a ser representada, dentre outras disposições específicas para cada categoria.

Uma rápida leitura das listas de auxílios dos anos de 1964 a 1966 revela uma mudança no processo, com o declínio significativo do número de contemplados (Auxílios 1962 a 1965, s.d.). Menos companhias profissionais foram beneficiadas,

\footnotetext{
12 Receberam amparo: o Teatro Jovem, o Teatro do Rio, o Teatro Carioca, o Teatro Santa Rosa, o Teatro de Bolso, o Teatro Miguel Lemos, a Companhia Milton Moraes, a Companhia Fábio Sabag, a Companhia Reinaldo Loio, o Teatro Princesa Isabel, o Teatro de Arena da Guanabara, o Teatro Cacilda Becker, o Teatro dos Sete, a Companhia Eva Todor, o Grupo Decisão, o Teatro do MAM, o Teatro Copacabana, o Teatro de Arena de São Paulo e a Companhia Maria Fernanda (Jornal do Brasil, 1964, p.13).

${ }^{13}$ Para ter uma ideia do custo de uma montagem, vale citar uma matéria de janeiro de 1965 em que Ruth Escobar menciona que uma produção custava em torno de 25 milhões de cruzeiros, tendo como folha de gastos mensais a quantia de 9 milhões. O Estado de S. Paulo. "Texto brasileiro substituirá no cartaz a “Ópera”". São Paulo, 28 jan. 1965, p.11.

${ }^{14}$ Foram contemplados: o Teatro Popular de Arte (TPA), o Teatro Brasileiro de Comédia (TBC), a EAD, o Teatro Oficina, as companhias de Ruth Escobar, Nydia Lícia, Florentino Lorent, Fernando D’Avila, Jean Luc Descaves, o Teatro de Arena e o Teatro Popular Nacional.
} 
com valores mais altos. Outro ponto que se destaca é que esses parecem ter alcançado as companhias preocupadas em fazer um teatro considerado de "alta qualidade artística”. No entanto, não se pode avançar na análise por não terem sido examinados os processos com pedidos de subvenção, o que daria uma dimensão maior das propostas em disputa, e, mais do que isso, da diversidade da produção teatral existente, ofuscada pela cristalização de uma memória, incorporada pela historiografia, que consagrou as experiências relacionadas à "resistência à ditadura", em detrimento de outras iniciativas (Guinsburg; Patriota, 2012, p.173).

As demais categorias também sofreram com a redução do número de selecionados, especialmente, a dos circos-teatros, o que, segundo a diretora ocorreu devido à falta de documentação e não em razão de critérios artísticos (Heliodora, 2013).

Assim, houve uma mudança nesta prática, sempre arbitrária, mas, a partir deste momento, distanciada do caráter assistencialista e quase "simbólico", que a caracterizou durante décadas, e orientada por uma visão de teatro marcada por um valor "civilizador" ou "educativo". Tal opção não estava isenta de questionamentos, pois, se a distribuição sem critério era problemática, ao decretar o "valor" de determinadas obras, o órgão público, de certa forma, desrespeitava a pluralidade do campo teatral, imbuído de uma noção de qualidade historicamente construída e passível de diferentes interpretações.

Uma das vozes a se levantar contra isso foi Dercy Gonçalves, que usou seu programa de televisão para criticar a diretora, gerando grande repercussão, de forma semelhante ao que ocorreu em outros episódios de contestação de critérios, comuns na história do órgão (Michalski, 1965, p.2; Camargo, 2017). ${ }^{15}$

Em meio a atitudes de apoio e críticas, Bárbara Heliodora conseguiu romper, ao menos temporariamente, com uma prática que estava consolidada, imprimindo sua marca na trajetória do órgão, ao concretizar, dentro das possibilidades, um "projeto coletivo" que, há muito, demandava essa reforma.

Outro grande foco de atuação da diretora foi o Conservatório Nacional de

15 Sobre o episódio ver também Amaral, 1994, p.232. 
Teatro. Como ela comentaria posteriormente, "a situação do Conservatório era um verdadeiro caos" e apresentava-se como um paradoxo, por ser, ao mesmo tempo, uma escola subordinada ao MEC via SNT, e não ter nenhuma base legal para o seu funcionamento (Heliodora, 1980, p.80).

A escola foi criada em 1939, com o nome de Curso Prático de Teatro, alterado para Conservatório Nacional de Teatro em 1953. Em sintonia com as transformações observadas na cena, a escola incorporou novos professores e disciplinas, realizou cursos experimentais, mas, sofreu com as descontinuidades administrativas, como todo o SNT (Castanheira, 2003, p.71-130). Entre 1963 e 1964, Roberto Freire iniciou uma série de estudos para a sua reformulação e conseguiu a regulação do registro de diplomas e cursos na Divisão de Educação Extraescolar do MEC (Lopes, 1980, p.58). Para isso, foi constituída uma comissão, composta pelos professores Maria Clara Machado, João Bethencourt, Maria Lília Nunes e Anízio Medeiros, que pesquisou programas de escolas norte-americanas, propostas e opiniões sobre o ensino de teatro. A comissão também contou com a consultoria de Luiza Barreto Leite, Gianni Ratto, do diretor da EAD Alfredo Mesquita, de ex-alunos da Escola de Teatro da Universidade da Bahia e do Curso de Artes Cênicas da Escola de Belas-Artes da Universidade do Recife, e do exdiretor Edmundo Moniz (Processo no 95/64).

Escapa aos limites deste artigo analisar detalhadamente as discussões, mas vale assinalar que os documentos que compõem o processo no 95/64 fornecem um amplo panorama sobre o ensino de teatro e sobre o próprio estatuto de uma escola teatral naquele momento. Neste se encontram posições divergentes acerca da inserção do curso de interpretação no ensino superior, sobre o "peso" das aulas teóricas na formação de profissionais teatrais, dentre outros pontos.

Neste processo há um projeto de portaria relativo aos novos currículos datados de março de 1964, mas que somente foi aprovado no ano seguinte. De acordo com este ato, havia no Conservatório os cursos de direção e cenografia, de nível universitário, de interpretação, de nível secundário, e cursos práticos para a formação de eletricista, figurinista, carpinteiro, contrarregra e aderecista (Brasil, 1965b, p.6.262). Entretanto, cabe atentar que, no folder Cursos do Conservatório Nacional de Teatro, de 1964, a oferta é maior, pois aparecem como cursos de nível 
secundário os de formação de contrarregras e de cenotécnicos, e dois cursos de extensão universitária, para a formação de professores de arte dramática e para administração teatral - informação que consta igualmente no histórico elaborado por Lopes (1980, p.58).

Ao assumir o SNT, Bárbara Heliodora retomou as discussões sobre o Conservatório. Em primeiro lugar, procurou uma nova sede, visto que o espaço utilizado estava sendo requisitado pelos proprietários (Cafezeiro, 1980, p.62). A solução encontrada foi a solicitação do prédio da UNE, na Praia do Flamengo, incendiado por simpatizantes do golpe civil-militar em 1o de abril de 1964, que dispunha de um teatro construído, em parte, com verbas concedidas pelo SNT (Laurence, 1964). ${ }^{16}$

A obtenção do edifício e a transferência da escola se efetuaram junto com a implementação da remodelação dos currículos, que culminaria na extinção do curso de coreografia, que funcionava precariamente e em desacordo com a legislação vigente, e com a elaboração de um projeto de lei de criação de profissionais teatrais sem o qual não seria possível regulamentar o ensino (Processo no 64/64; Heliodora, 1966).

A lei no 4.641, de 27 de maio de 1965, conhecida na época como "Lei Castelo Branco", dispôs sobre os cursos de teatro e regulamentou as categorias de diretor, cenógrafo, professor de arte dramática, ator, contrarregra, cenotécnico e sonoplasta. Para as três primeiras foram previstos cursos de nível superior e para as restantes, de nível secundário. O mesmo ato determinou que os cursos deveriam ser registrados no MEC para que os diplomas tivessem efeito legal, e que os profissionais que exercessem essas profissões há mais de dois anos, mas que não tivessem diplomas, requisitassem um registro para continuar trabalhando (Brasil, 1965a, p.5.137).

Na exposição de motivos que acompanhou o projeto de lei foi apresentada, dentre outras justificativas, a necessidade de ordenar e atualizar o ensino teatral, "revestindo-o do pragmatismo exigido pela época", que contribuiria para a valorização dessas carreiras e ampliação de seu mercado de trabalho (Brasil,

${ }^{16}$ Sobre o prédio, ver Ensaio/Teatro, 1980. 
1965c).

A lei não foi regulamentada naquele momento. Houve críticas e muitas divergências que impediram seu cumprimento no que se referia à profissionalização, ainda que as questões relacionadas ao ensino tivessem avançado, pelo menos no que se refere ao próprio Conservatório do SNT (Cafezeiro, 1980, p.63; Jornal do Brasil, 1965, p.11; Maciel, 1968, p.58). Vale lembrar que em 1978 uma nova lei, no 6.533, trataria das profissões de artista e de técnico em espetáculos de diversões, e seria regulamentada no mesmo ano, o que demonstra que o ato de 1965, em parte, "não saiu do papel", indicando as dificuldades desse processo dentro e fora do campo teatral.

Em 1965, o Conselho Federal de Educação estabeleceu os conteúdos mínimos dos cursos de direção, cenografia e de formação de professores de arte dramática com base nos programas do Conservatório, tornando a instituição federal a referência de modelo pedagógico que deu origem aos cursos superiores de teatro nos anos seguintes (Koudela; Santana, 2013, p.449).

Na tentativa de tornar mais adequada a situação do Conservatório, a diretora instituiu uma comissão para estudar sua transformação em fundação, que não resultou em desdobramentos (Heliodora, 1980, p.82). Apenas em 1969, o Conservatório seria transferido para a Federação das Escolas Federais Isoladas do Estado da Guanabara (FEFIEG), atual UNIRIO, onde existe até hoje.

Além desses dois grandes focos, Bárbara Heliodora foi responsável pela execução do concurso de peças, idealizado por Roberto Freire, que premiou originais brasileiros com sua publicação e apoio à montagem. A peça vencedora em 1966, Rasto Atrás, de Jorge Andrade, foi o último espetáculo realizado pela companhia oficial, o Teatro Nacional de Comédia, dirigido por Gianni Ratto. A outra peça montada pelo TNC durante a gestão de Bárbara Heliodora foi O noviço, de Martins Pena, dirigida por Dulcina de Moraes (Michalski; Trotta. 1992, p.174-180).

A diretora promoveu o Festival Martins Pena, voltado para grupos amadores de todo o país, e deu continuidade a publicação de livros, incluindo a revista Dionysos. Sobre a questão da formação das plateias, não foram empreendidas iniciativas, nem mesmo a elaboração de cursos similares aos realizados pelo CICT. 
A ampliação das ações do órgão também ficou relegada a um segundo plano. Bárbara Heliodora manteve as delegacias estaduais, visitou algumas cidades e tomou algumas medidas pontuais, sem, contudo, imprimir nenhuma diretriz de atuação regional (Heliodora, 1967).

Ao lado das medidas de promoção, o teatro foi objeto de atenção do aparelho repressor. O aumento das ações de censura mobilizou o setor teatral que protestou, várias vezes, contra os abusos cometidos (Michalski, 1985, p.25). Em 1967, o Departamento Federal de Segurança Pública (DFSP) procurou o SNT, resultando na elaboração de um curso de especialização teatral para contribuir para a formação dos censores, que ficou a cargo de Bárbara Heliodora, Gustavo Dória e Henrique Oscar (Garcia, 2008, p.207). Essa "parceria” da Polícia com o SNT gerou críticas do setor. No início de março, o Jornal do Brasil afirmou que a diretora havia encarado a questão com "otimismo" (Jornal do Brasil, 1967, p.14). Quatro dias depois, o mesmo jornal publicou uma carta de resposta de Bárbara Heliodora sobre a matéria, na qual solicitou que o jornal "não confundisse seu desencanto com otimismo", posicionando-se "visceralmente contra a censura. Não esta ou aquela censura mas toda a censura, por questão de princípio" (Jornal do Brasil, 1967, p.6). A diretora também explicou que, pela primeira vez, o órgão dedicado ao teatro havia sido procurado pela Polícia, e que o objetivo do curso era "debater precisamente os problemas de qualidade, integridade da obra de arte e respeito a liberdade do artista e de julgamento por parte do público" (Jornal do Brasil, 1967, p.6).

Bárbara Heliodora deixou o SNT logo depois, em 31 de março. Posteriormente, atuou, junto com a classe teatral, nas lutas contra a censura, exercendo um papel de liderança em algumas ocasiões, e defendeu a liberdade de expressão em seus artigos na imprensa (Garcia, 2008, p.53-65).

O balanço de sua administração foi favorável para alguns, como Luiza Barreto Leite, que assinalou: "em um país onde todos sabem o que fazer, mas ninguém faz, foi uma surpresa verificar que a diretora começou a realizar exatamente o que sempre aconselhara aos outros realizarem" (Leite, 1965, p.114). Mas, igualmente, sofreu críticas relacionadas aos critérios para as subvenções, à tentativa de regulamentar a profissão, ao tratamento concedido aos grupos amadores, dentre 
outros aspectos que merecem ser estudados com maior profundidade, a fim de se avaliar as lutas do campo teatral e as suas relações com o órgão federal em um momento singular de sua longa história.

Ela mesma admitiu as dificuldades e os poucos resultados de sua gestão, especialmente em razão da exiguidade das verbas:

Acima de tudo, o SNT sempre sofreu, de forma particularmente aguda, daquela doença endêmica que grassa nos órgãos governamentais do país, a falta de verbas. Sofreu também, muitas vezes, de falta de visão teatral, favoritismo agudo, paralisia burocrática, e falta de definição. [...]. A falta de verbas reflete, com perfeita fidelidade, a falta de importância que é dada ao órgão na estrutura do MEC (2007, p.752). ${ }^{17}$

Ao fazer um balanço sobre sua direção na entrevista concedida em 2013, Bárbara Heliodora disse ter tentado fazer um trabalho mais objetivo, mas que "não foi nenhuma maravilha”, reiterando as dificuldades enfrentadas, a resistência de alguns funcionários pelo fato dela ter "saído do modelo clássico" de administração, e o pouco apoio do ministério: "A verdade é essa, o MEC não tinha interesse pelo teatro" (Heliodora, 2013).

Na ausência de uma política governamental, a crítica, como os outros diretores do órgão, estabeleceu prioridades pautadas na sua concepção do que seria a forma mais adequada de ação de um órgão público voltado para o teatro.

Desse modo, pode-se concluir que Bárbara Heliodora alcançou algum êxito em sua atuação, promovendo mudanças, ainda que de caráter limitado, ao transformar a prática da subvenção e ao implementar medidas destinadas ao aprimoramento e oficialização da escola de teatro, que teriam alcance a longo prazo. Se, por um lado, afastou-se do setor ao extinguir uma instância de representação, por outro, viabilizou um "projeto" para impulsionar, com as parcas verbas disponíveis, um teatro “de alto nível”, capaz de contribuir, segundo ela, para a educação do público e dos próprios artistas e profissionais de teatro.

17 O Mistério Insondável do SNT [20 jul. 1968]. 


\section{Considerações finais}

Esse breve panorama sobre um capítulo da trajetória de um órgão de fomento ao teatro buscou refletir sobre algumas discussões presentes no longo e descontínuo caminho de construção e legitimação da área como objeto de políticas públicas. Com isso, pretendeu-se assinalar a importância da análise de iniciativas pioneiras a fim de dimensionar a complexidade desse processo, marcado por orientações personalistas de caráter temporário, interferências de autoridades superiores, estruturas administrativas limitadas, dificuldades de diálogo com o setor, entre outros fatores. Tais questões acabaram por fragilizar grande parte das experiências realizadas, que ainda são pouco conhecidas entre os pesquisadores, embora sejam essenciais para conferir uma perspectiva mais ampliada aos estudos sobre a história do teatro no Brasil.

\section{Referências}

AMARAL, Maria Adelaide. Dercy de cabo a rabo. São Paulo: Globo, 1994.

AUXÍliOS 1962 a 1965. Pasta Auxílios. Serviço Nacional de Teatro (Cedoc/Funarte).

BERNSTEIN, Ana; JUNQUEIRA, Christine. A crítica teatral moderna. In: FARIA, João Roberto (dir.). História do teatro brasileiro, v. 2: do modernismo às tendências contemporâneas. São Paulo: Perspectiva; Edições SESCSP, 2013, p.161-174.

BETTI, Maria Sílvia. O teatro da resistência. In: FARIA, João Roberto (dir.). História do teatro brasileiro, v. 2: do modernismo às tendências contemporâneas. São Paulo: Perspectiva; Edições SESCSP, 2013, p.215-239.

BRAGA, Cláudia (org.). Barbara Heliodora: escritos sobre teatro. São Paulo: Perspectiva, 2007.

BRASIL. Lei no 4.641, de 27 de maio de 1965. Dispõe sobre os cursos de teatro e regulamenta as categorias profissionais correspondentes. Diário Oficial da República dos Estados Unidos do Brasil. Poder Executivo, Brasília, DF, 31 maio 1965a. Seção 1, p.5.137.

BRASIL. Ministério da Educação e Cultura. Portaria no 614, de 16 de setembro de 1964. Diário Oficial da República dos Estados Unidos do Brasil. Poder Executivo, Brasília, DF, 24 set. 1964. Seção 1, p.8.585. 
BRASIL. Serviço Nacional de Teatro. Portaria no 10, de 4 de março de 1965. Diário Oficial da República dos Estados Unidos do Brasil. Poder Executivo, Brasília, DF, 5 jul. 1965b. Seção 1, p.6.262-6.263.

BRASIL. Projeto de lei no 2.592/1965c. Disponível em: https://bit.ly/3x5yq8D. Acesso em: 6 jun. 2021.

CAFEZEIRO, Edwaldo. Sem estudante não existe escola. Entrevista concedida a Carmen Gadelha e Fátima Saadi. Ensaio/Teatro, Rio de Janeiro, n. 5, p. 60-67,1980.

CALABRE, Lia. Políticas culturais no Brasil: dos anos 1930 ao século XXI. Rio de Janeiro: Editora FGV, 2009.

CAMARGO, Angélica Ricci. Por um Serviço Nacional de Teatro: debates, projetos e o amparo oficial ao teatro no Brasil (1946-1964). 2017. Tese (Doutorado em História Social) - Instituto de História - Universidade Federal do Rio de Janeiro, Rio de Janeiro, 2017.

CASTANHEIRA, Jana Eiras. Do curso prático ao conservatório: origens da Escola de Teatro da UNIRIO. 2003. Dissertação (Mestrado em Teatro) - Escola de Teatro Universidade Federal do Estado do Rio de Janeiro, Rio de Janeiro, 2003.

CRUZ, Maria Eugênia de Araújo Rodrigues. Comissão Estadual de Teatro de São Paulo (1956-1960): um modelo de política cultural em relação ao teatro. 2000. Dissertação (Mestrado em Artes) - Escola de Comunicação e Artes - Universidade de São Paulo, São Paulo, 2000.

DA RIN, Márcia. Crítica: a memória do teatro brasileiro. Percevejo: Revista de Teatro, Crítica e Estética, Rio de Janeiro, n. 3, ano 3, p.40-42, 1995.

DENIZOT, Marion. Jeanne Laurent: une fondatrice du service public pour la culture 1946-1952. Paris: Comité d'histoire du ministère de la Culture, 2005.

DIONYSOS. SNT: Trinta anos de atividades. Rio de Janeiro, ano XII, n. 15, p.54-86, dezembro de 1967.

DUBOIS Vincent. La politique culturelle: genèse d'une catégorie d'intervention publique. Paris: Belin, 1999.

GARCIA, Miliandre. "Ou vocês mudam ou acabam": teatro e censura na ditadura militar (1964-1985). 2008. Tese (Doutorado em História Social) - Instituto de Filosofia e Ciências Sociais - Universidade Federal do Rio de Janeiro, Rio de Janeiro, 2008.

GARCIA, Miliandre. Políticas culturais no regime militar: a gestão de Orlando Miranda no SNT e os paradoxos da hegemonia cultural de esquerda (1974-1979). In: NAPOLITANO, Marcos; CZAJKA, Rodrigo; MOTTA, Rodrigo Patto Sá (Orgs.). Comunistas brasileiros: cultura política e produção cultural. Belo Horizonte: UFMG, 2013, p.131-151. 
GOMES, Ângela de Castro; HANSEN, Patrícia. Intelectuais, mediação cultural e projetos políticos: uma introdução para a delimitação do objeto de estudo. In: GOMES, Ângela de Castro; HANSEN, Patrícia (org.). Intelectuais mediadores: projetos culturais e ação política, Rio de Janeiro, Ed. Civilização Brasileira, 2016, p.7-37.

GUINSBURG, J.; PATRIOTA, Rosangela. Teatro brasileiro: ideias de uma história. São Paulo: Editora Perspectiva, 2012.

GUZIK, Alberto. Guzik, A. Em busca de um teatro de qualidade. Revista USP, São Paulo, n.78, p.140-150, 2008.

HELIODORA, Bárbara. Bárbara Heliodora - 91 anos, escritora e tradutora. Entrevista. Mais 60: estudos sobre envelhecimento. São Paulo: Sesc São Paulo, v. 25, n. 60, p. 88-99, jul. 2014. Disponível em: https://bit.ly/3ghK9Kx. Acesso em: 15 maio 2021.

HELIODORA, Bárbara. Entrevista concedida à Associação Brasileira de Imprensa. In: ABI. Disponível em: https://bit.ly/3cmawgY. Acesso em: 15 maio 2021.

HELIODORA, Bárbara. Entrevista concedida à Angélica Ricci Camargo, em 17 jun. 2013.

HELIODORA, Bárbara. Foi um esforço considerável tentar botar a escola funcionando. Entrevista concedida a Ângela Leite Lopes. Ensaio/Teatro, Rio de Janeiro, n. 5, p.79-84, 1980.

HELIODORA, Bárbara. Relatório das atividades do SNT de 1965, de 28 de janeiro de 1966. Pasta Relatórios. Serviço Nacional de Teatro (Cedoc/Funarte).

HELIODORA, Bárbara. Relatório das atividades do SNT de 1964 a 1967, de 21 de março de 1967. Pasta Relatórios. Serviço Nacional de Teatro (Cedoc/Funarte).

JORNAL DO BRASIL. "Artistas cariocas acham censores imbecis e nova lei, "rolha de champanha”. Rio de Janeiro, 7 mar. 1967, p.14.

JORNAL DO BRASIL. "Bárbara entrega a teatros subvenção de 6 milhões concedida pelo presidente”. Rio de Janeiro, 11 dez. 1964, p.13.

JORNAL DO BRASIL. "Carta aos leitores”. Rio de Janeiro, 11 mar. 1967, p.6.

JORNAL DO BRASIL. "Mensagem regulamentando as profissões teatrais ainda não foi aprovada". Rio de Janeiro, 6 mar. 1965, p.11.

JORNAL DO BRASIL. "Objetivo de Bárbara no SNT é dinamizar o ensino de teatro em todo o país". Rio de Janeiro, 24 maio 1964, p.13.

JUNQUEIRA, Christine. CICT versus ABCT: a polêmica da crítica teatral carioca da década de 1950. O Percevejo: revista de teatro, crítica e estética, Rio de Janeiro, n. 
13, p.189-204, 2004.

KOUDELA, Ingrid Dormien; SANTANA, Arão Paranaguá de. O teatro na educação. In: FARIA, João Roberto (dir.). História do teatro brasileiro, v. 2: do modernismo às tendências contemporâneas. São Paulo: Perspectiva; Edições SESCSP, 2013, p.446458.

LAURENCE, Jacqueline. Movimento Teatral. Notícias do SNT. Cadernos de Teatro, Rio de Janeiro, n. 27, jul./set. 1964.

LEÃO, Liana de Camargo. Bárbara Heliodora. In: NEVES, José Roberto de Castro (org.). Brasileiros. Rio de Janeiro: Editora Nova Fronteira, 2020, p.107-126.

LEITE, Luiza Barreto. A mulher no teatro brasileiro. Rio de Janeiro: Edições Espetáculo, 1965.

LEITE, Luiza Barreto. "Subvenção não é prêmio de bom comportamento". Revista de Teatro da SBAT, Rio de Janeiro, n. 340, p.15-20, jul./ago. 1964.

LIMA, Erickaline Bezerra de; CIOTTI, Naira Neide. Críticos teatrais em ação: luta e organização política em prol da modernidade cênica brasileira. Urdimento - Revista de Estudos em Artes Cênicas, Florianópolis, v. 2, n. 27, p.327-338, 2016. Disponível em: https://bit.ly/35BELgj. Acesso em: 20 jun. 2021.

LIMA FILHO, Francisco Geraldo de Magela. Notas sobre o papel (e o lugar) do crítico teatral. Passagens, Fortaleza, v. 9, n. 1, p.50-58, 2018.

LOPES, Ângela Leite. Do curso prático à escola de teatro: quarenta anos de improvisação. Ensaio/Teatro, Rio de Janeiro, n. 5, p.56-59, 1980.

LOPES, Caroline Cantanhede. Guardar para todos a memória de muitos: projetos e políticas para a preservação da memória das artes cênicas no Brasil. 2020. Tese (Doutorado em História) Universidade Federal do Estado do Rio de Janeiro, Rio de Janeiro, 2020.

LUGÃO, Juliana Serôa da Motta. Bárbara Heliodora: uma trajetória crítica. Trabalho de Conclusão de Curso (Graduação em Comunicação) - Escola de Comunicação Universidade Federal do Rio de Janeiro, Rio de Janeiro, 2006.

MACIEL, Luiz Carlos. Quem é quem no teatro brasileiro. Revista Civilização Brasileira, Rio de Janeiro, Caderno Especial, n. 2, p.49-68, julho, 1968.

MAIA, Tatyana de Amaral. Os cardeais da cultura nacional: o Conselho Federal de Cultura na ditadura civil-militar (1967-1975). São Paulo: Itaú Cultural; Iluminuras, 2012.

MENDONÇA, Bárbara Heliodora Carneiro de. Carta [1961]. Pasta relatórios. Serviço Nacional de Teatro (Cedoc/Funarte). 
MICELI, Sérgio. As tradições do mecenato europeu nos campos das artes cênicas, da música e de rádiotelevisão. In: MICELI, Sérgio; GOUVEIA, Alice. Política Cultural Comparada. Rio de Janeiro: FUNARTE; FINEP; IDESP, 1985 p.9-33.

MICHALSKI, Yan. Bárbara no Serviço. Jornal do Brasil, Rio de Janeiro, 27 maio 1964. Caderno B, p. 3.

MICHALSKI, Yan. Derci, nada espetacular. Jornal do Brasil, Rio de Janeiro, 31 maio 1965. Caderno B, p.2.

MICHALSKI, Yan. O teatro sob pressão: uma frente de resistência. Rio de Janeiro: Jorge Zahar Ed.,1985.

MICHALSKI, Yan; TROTTA, Rosyane. Teatro e Estado: As Companhias Oficiais de Teatro no Brasil: história e polêmica. São Paulo: Editora HUCITEC; IBAC, 1992.

MOURA, Gerson. Paulo Francis, o soldado fanfarrão. 2. ed. Rio de Janeiro: Editora Objetiva, 1996.

NAPOLITANO, Marcos. Coração civil: A vida cultural brasileira sob o regime militar (1964-1985) - ensaio histórico. São Paulo: Intermeios: USP, 2017.

O ESTADO DE S. PAULO. "Concedida ajuda federal ao teatro de São Paulo". São Paulo, 7 fev. 1965, p.11.

O ESTADO DE S. PAULO. “Texto brasileiro substituirá no cartaz a "Ópera”". São Paulo, 28 jan. 1965, p.11.

OSCAR, Henrique. Entrevista concedida à Bárbara Heliodora, Maria Clara Machado e outros. In: BRASIL. Ministério da Educação e Cultura. Fundação Nacional de Arte. Serviço Nacional de Teatro. Depoimentos, v. II. Rio de Janeiro, 1977, p.55-69.

PONTES, Heloísa. Intérpretes da metrópole: História social e relações de gênero no teatro e no campo intelectual, 1940-1968. São Paulo: Editora da Universidade de São Paulo/Fapesp, 2010.

PROCESSOS no 64/64, no 95/64, no 157/64, no 476/64. Serviço Nacional de Teatro (Cedoc/Funarte).

RUBIM, Antonio Albino Canela. Políticas culturais no Brasil: itinerários e atualidade. In: BOLAÑO, César; GOLIN, Cida; BRITTOS, Valério (orgs.). Economia da arte e da cultura. São Paulo: Itaú Cultural; São Leopoldo: Cepos/Unisinos; Porto Alegre: PPGCOM/UFRGS; São Cristóvão: Obscom/UFS, 2010, p.51-71.

SERVIÇO Nacional de Teatro. Cursos do Conservatório Nacional de Teatro, 1964 [folder]. Fundo Labanca (Cedoc/Funarte).

TORRES, Fernanda. Tia Bárbara, a temível. Revista Piauí, edição 104, maio 2015. Disponível em: https://bit.ly/2Sc1BYH. Acesso: 5 jun. 2021. 
VELHO, Gilberto. Trajetória individual e campo de possibilidades. In: VELHO, Gilberto. Projeto e Metamorfose: Antropologia das sociedades complexas. Rio de Janeiro: Jorge Zahar Ed., 1994, p.31-48.

WOLFF, Fausto. Ministro Lacerda de parabéns. Tribuna da Imprensa, Rio de Janeiro, 18 maio 1964, p.2.

Recebido em: 24/06/2021

Aprovado em: 28/09/2021 